\title{
Quality of life in patients with chronic obstructive pulmonary disease improves after rehabilitation at home
}

\author{
P.J. Wijkstra*, R. Van Altena*, J. Kraan**, V. Otten*, D.S. Postma**, G.H. Koëter**
}

\begin{abstract}
Quality of life in patients with chronic obstructive pulmonary disease improves after rehabilitation at home. P.J. Wijkstra, R. Van Altena, J. Kraan, V. Otten, D.S. Postma, G.H. Koëter. CERS Journals Ltd 1994.

ABSTRACT: We have developed a rehabilitation programme at home and have investigated its effects on quality of life (QOL), lung function, and exercise tolerance in patients with chronic obstructive pulmonary disease (COPD).

We studied 43 patients with severe airflow obstruction: forced expiratory volume in one second $\left(F E V_{1}\right) 1.3 \pm 0.4 l\left(\right.$ mean \pm SD), $F E V_{1}$ /inspiratory vital capacity (IVC) $37 \pm 7.9 \%$. After stratification, 28 patients were randomly allocated in a home rehabilitation programme for 12 weeks. Fifteen patients in a control group received no rehabilitation. The rehabilitation group received physiotherapy by the local physiotherapist, and supervision by a nurse and a general practitioner. Quality of life was assessed by the four dimensions of the Chronic Respiratory Questionnaire (CRQ).

We found a highly significant improvement in the rehabilitation group compared to the control group for the dimensions dyspnoea, emotion, and mastery. Lung function showed no changes in the rehabilitation group. The exercise tolerance improved significantly in the rehabilitation group compared to the control group. The improvement in quality of life was not correlated with the improvement in exercise tolerance.

Rehabilitation of COPD patients at home may improve quality of life; this improvement is not correlated with an improvement in lung function and exercise tolerance. Eur Respir J., 1994, 7, 269-273.
\end{abstract} \author{
The Netherlands. \\ Correspondence: P.J. Wijkstra \\ Beatrixoord Hospital \\ 9751 ND Haren (Groningen) \\ The Netherlands
}

*Asthma Centre Beatrixoord, Haren, The Netherlands. **Dept of Pulmonary Diseases, University Hospital Groningen,

Keywords: Chronic obstructive pulmonary disease

quality of life

rehabilitation at home

Received: February 171993

Accepted after revision September 191993

Supported by a grant from the Nederlands Astma Fonds (grant no. 89.29) and the Foundation Astmabestrijding.
Patients with chronic obstructive pulmonary disease (COPD) are characterized by an impaired lung function and a limited exercise tolerance. Medication and rehabilitation programmes are generally directed towards relief of symptoms and improvement of lung function and exercise tolerance. Several studies have shown, however, that COPD may also lead to an impaired quality of life [1-3]. Health care use by COPD patients appears to be related even more to an impaired quality of life than to the severity of the lung disease itself [4]. Therefore, improvement in quality of life should be one of the aims of treatment of COPD [5].

Two general health measurements, the Quality of Wellbeing Scale [6] and the Sickness Impact Profile (SIP) [7], have been used in COPD patients [1-3] in this respect. However, their use may be limited by a lack of sensitivity to detect changes in health [8]. A disease-specific questionnaire may be more sensitive, as a higher proportion of its content is pertinent to the disease itself [8]. However, the most comprehensive disease-specific measurement available in COPD at the time of the study, the Chronic Respiratory Questionnaire (CRQ) of GuYATT and co-workers [9], showed no improvement of quality of life after inspiratory muscle training in COPD patients [10].
The purpose of the present study was to investigate, in patients with COPD, whether a more extensive home rehabilitation programme could show improvement in quality of life, as measured with the CRQ.

\section{Patients and Methods}

\section{Patients}

We studied 45 COPD patients (all smokers or exsmokers) (table 1) with severe airflow limitation. All patients were in a clinically stable condition (no recent exacerbations) with optimal drug management. Entry criteria were: 1) forced expiratory volume in one second $\left(\mathrm{FEV}_{1}\right)<60 \%$ predicted; and 2) $\mathrm{FEV}_{1}$ /inspiratory vital capacity (IVC) $<50 \%$; both after two inhalations of $40 \mu \mathrm{g}$ ipratropium bromide. Patients with evidence of ischaemic heart disease, intermittent claudication, musculoskeletal disorders, or other disabling diseases that could restrict the rehabilitation programme were excluded. The study was approved by the Medical Ethics Committee of the University Hospital of Groningen, and all patients gave informed consent. 
Table 1. - Baseline characteristics of the study population

\begin{tabular}{lcc}
\hline & $\begin{array}{c}\text { Rehabilitation } \\
\text { group }\end{array}$ & $\begin{array}{c}\text { Control } \\
\text { group }\end{array}$ \\
\hline $\mathrm{n}$ & 28 & 15 \\
Gender M/F & $23 / 5$ & $14 / 1$ \\
Age yrs & $64 \pm 5$ & $62 \pm 5$ \\
$\mathrm{FEV}_{1} \mathrm{~b} l$ & $1.2 \pm 0.3$ & $1.2 \pm 0.3$ \\
$\mathrm{FEV}_{1} \mathrm{a} l$ & $1.3 \pm 0.4$ & $1.4 \pm 0.3$ \\
$\mathrm{FEV}_{1} \%$ pred & $44 \pm 11$ & $45 \pm 9$ \\
$\mathrm{FEV}_{1} / \mathrm{IVC} \%$ & $39 \pm 8$ & $36 \pm 7$ \\
$\mathrm{IVC}_{\mathrm{T}} \%$ pred & $84 \pm 16$ & $94 \pm 15^{*}$ \\
$\mathrm{TLC} \%$ pred & $118 \pm 14$ & $114 \pm 11$ \\
$\mathrm{RV} / \mathrm{TLC} \%$ pred & $151 \pm 24$ & $133 \pm 18^{*}$ \\
$\mathrm{Cst} l \cdot \mathrm{kPa}-1$ & $4.3 \pm 3.1$ & $5.3 \pm 3.0$ \\
TLCO/VA \% pred & $65 \pm 23$ & $65 \pm 25$ \\
\hline
\end{tabular}

All value are expressed as mean \pm SD. $*: \mathrm{p}<0.05$ unpaired $\mathrm{t}$ test. FEV $\mathrm{b}$ : forced expiratory volume in one second before bronchodilation with two inhalations of $40 \mu \mathrm{g}$ ipratropium bromide; $\mathrm{FEV}_{1} \mathrm{a}$ : $\mathrm{FEV}_{1}$ after bronchodilation; \% pred: expressed as a percentage of the predicted value; $\mathrm{FEV}_{1} / \mathrm{IVC} \%$ : $\mathrm{FEV}_{1}$ expressed as a percentage of the slow inspiratory vital capacity; TLC: total lung capacity; RV: residual volume; Cst: static lung compliance; TLCO/VA: transfer factor for carbon monoxide divided by alveolar volume.

\section{Study design}

The patients were hospitalized for two days for their initial evaluation. They were stratified for their $\mathrm{FEV}_{1} \%$ predicted (less or more than $45 \%$ predicted), their limiting factor in exercise capacity (ventilatory limitation or nonventilatory limitation), and the maximal workload (less or more than $70 \mathrm{w}$ ) of their cycle ergometer test. After this stratification, the patients were randomly allocated to a 12 week home rehabilitation programme or to a control group. Thirty patients entered the rehabilitation group and 15 patients entered the control group. The following measurements were carried out before, and 12 weeks after, rehabilitation: 1) quality of life; 2) spirometry; and 3) cycle ergometer test.

\section{Rehabilitation programme}

The patients were supervised by a multidisciplinary team: pulmonologist, physiotherapist, nurse, and general practitioner. The study was organized and set up by one pulmonologist (P.J.W.), who visited all physiotherapists, nurses, and general practitioners before the start of the study to instruct them about the rehabilitation programme. The patients visited the physiotherapist twice a week for 12 weeks.

The physiotherapy programme consisted of conventional physiotherapy (relaxation exercises [11], and breathing retraining [12]), upper limb training [13], target-flow inspiratory muscle training (IMT) [14], and exercise training on a home-trainer according to Allison et al. [15]. The patients started exercise training for $4 \mathrm{~min}$ at $60 \%$ of their maximal workload (Wmax) of the cycle ergo- meter test. The time span was gradually extended to 12 min and the workload to a maximum of $75 \%$ of the Wmax. All exercises were taught by the physiotherapist. The patients had to practise twice a day for half an hour at home, according to an individualized protocol. During this training period of one hour a day, all exercises were practised. Patients started one day with relaxation exercises and the other day with breathing retraining, and so on. Every day they practised IMT, upper limb training, and exercise training on a home-trainer.

In addition to this physical training, the patients were supervised once a month by a nurse and a general practitioner. The nurse visited the patients at home, and her task was to give the patients and also family members a better insight into the possible disabilities and handicaps due to impairment of the lungs. Information was given about pulmonary disease, about various strategies for treatment, how to use the medication, how the patient could cope with the disease, and the role of a rehabilitation programme in this coping strategy.

The patients also visited the general practitioner once a month, and his task was to supervise the clinical status and maintenance treatment. The control group did not follow the above mentioned protocol.

\section{Outcome measures}

Baseline lung function characteristics. Static lung volumes, $\mathrm{FEV}_{1}$, IVC, diffusion capacity, volume-pressure relationship, and static compliance were measured during the initial evaluation. Static lung volumes were determined in a constant volume whole body plethysmograph (Masterlab, Jaeger, Würzburg, FRG). $\mathrm{FEV}_{1}$ and IVC were measured by means of a pneumotachograph (Jaeger, Würzburg, FRG). Diffusion transfer factor for carbon monoxide divided by alveolar volume $\left(\mathrm{TLCO} / \mathrm{VA}_{\mathrm{A}}\right)$ was measured by using the single-breath method. Volume/pressure (V/P) diagrams of the lungs were recorded using an oesophageal balloon (Jaeger, Würzburg, FRG). Static compliance was calculated from the V/P diagram. Predicted values were derived from the European Community for Coal and Steel (ECCS) [16].

Quality of life. Quality of life was assessed by the Chronic Respiratory Questionnaire (CRQ) of GuYATT and coworkers [9], which was translated into Dutch. The CRQ is divided into four dimensions: Dyspnoea, Fatigue, Emotion, and Mastery. The dimensions Fatigue, Emotion and Mastery had a good reliability, whilst the dimension Dyspnoea showed a lower reliability (submitted for publication). This questionnaire was also shown to be valid given the good correlation with the dimensions of the Symptom Checklist [17] (SCL-90) (submitted for publication). The CRQ measures both physical and emotional function. Physical function was investigated by five items relating to the dimension dyspnoea and by four items relating to the dimension Fatigue. Assessment of emotional function, corresponding with the dimensions Emotion and Mastery, included questions about frustration, depression, anxiety, panic, and fear of dyspnoea. 
Patients were asked to rate their physical and emotional function on a seven point scale. Higher scores represented better function. During the second administration of the test (after 12 weeks), the patients were told their previous answers (from the start of the programme), as advocated by GUYATT and co-workers [18].

Spirometry. After 12 weeks, $\mathrm{FEV}_{1}$ and IVC were measured by means of a pneumotachograph.

Cycle ergometer test. Patients respired through a mouthpiece and wore a noseclip during the incremental symptomlimited cycle ergometer test (Jaeger, Würzburg, FRG). Minute ventilation $\left(\dot{\mathrm{V}}_{\mathrm{E}}\right)$, oxygen uptake $\left(\dot{\mathrm{V}}_{2}\right)$ and carbon dioxide output $\left(\dot{\mathrm{V}}_{\mathrm{CO}}\right)$ were measured every 30 s from analysis of the expirate by a computerized system (EOS Sprint; Jaeger, Würzburg, FRG). Heart rate was monitored simultaneously (Marquette Electronics inc., Milwaukee, USA), and arterial oxygen saturation $\left(\mathrm{SaO}_{2}\right)$ was recorded continuously by an ear oximeter (Biox IIA, Biox Technology inc., Colorado, USA). After 1 min of unloaded pedalling, work rate increased $10 \mathrm{w}$ every minute. Patients were instructed to stop when they could not continue the test any longer due to dyspnoea or general fatigue. The maximum workload (Wmax) was defined as the highest work level reached and maintained for a full minute.

\section{Statistical analysis}

After checking for a normal distribution, baseline outcome measures between the two groups were analysed with unpaired Student's t-test, while the results after 12 weeks were compared with baseline within each group using a paired t-test. The changes in each variable in the rehabilitation group compared to the control group were investigated by the unpaired Student's t-test. Significance level was set at $\mathrm{p}<0.05$.

\section{Results}

Two patients dropped out of the rehabilitation group: one patient due to a cerebral tumour and one due to arthritis. The rehabilitation group, therefore, consisted of 28 patients and the control group of 15 .

\section{Outcome measures}

Baseline lung function characteristics. These showed no significant differences between the rehabilitation and the control group, except for IVC and (RV)/(TLC) \% predicted (table 1). The measurements in both groups concerning quality of life and exercise tolerance were comparable at baseline.

Quality of life. The dimensions Dyspnoea, Fatigue, Emotion, and Mastery showed a highly significant $(\mathrm{p}<0.001)$ improvement after 12 weeks of rehabilitation as compared to baseline, whilst there was no change in the control group (table 2). The change in the dimensions Dyspnoea, Emotion and Mastery was also significantly $(\mathrm{p}<0.01)$ different between both groups.

Table 2. - Effects of rehabilitation on quality of life

\begin{tabular}{lllll}
\hline & \multicolumn{2}{c}{ Rehabilitation group } & \multicolumn{2}{c}{ Control group } \\
& Baseline & 12 week & Baseline & 12 week \\
\hline Dyspnoea & $19.6 \pm 4.6$ & $23.9 \pm 5.1^{* * *}$ & $19.3 \pm 5.8$ & $19.1 \pm 6.6^{\# \#}$ \\
Fatigue & $16.2 \pm 5.3$ & $19.7 \pm 5.2^{* * *}$ & $15.9 \pm 4.7$ & $16.9 \pm 4.3$ \\
Emotion & $34.8 \pm 7.4$ & $38.7 \pm 6.9^{* * *}$ & $32.9 \pm 6.7$ & $33.1 \pm 6.5^{\text {\#\# }}$ \\
Mastery & $20.1 \pm 4.8$ & $22.5 \pm 4.5^{* * *}$ & $20.3 \pm 4.0$ & $20.3 \pm 4.1^{\# \#}$ \\
\hline
\end{tabular}

All values are expressed as mean $\pm \mathrm{SD}, * * *: \mathrm{p}<0.001$ paired $\mathrm{t}$ test between baseline and 12 week test; \#\#: $p<0.01$ unpaired ttest between the changes in both groups. Dyspnoea, Fatigue, Emotion and Mastery: dimensions of the Chronic Respiratory Questionnaire.

Spirometry: $\mathrm{FEV}_{1}$ and IVC in the control group were significantly $(\mathrm{p}<0.05$ and $\mathrm{p}=0.001$, respectively) lower after 12 weeks compared to baseline (table 3 ). The change in IVC was significantly $(\mathrm{p}<0.05)$ different between both groups.

Table 3. - Effects of rehabilitation on lung function and exercise capacity

\begin{tabular}{lcccc}
\hline & \multicolumn{2}{c}{ Rehabilitation group } & \multicolumn{2}{c}{ Control group } \\
& Baseline & 12 week & Baseline & 12 week \\
\hline IVC $l$ & $3.4 \pm 0.9$ & $3.3 \pm 0.8$ & $3.9 \pm 0.9$ & $3.5 \pm 0.9 * * * \#$ \\
FEV $_{1} \quad l$ & $1.3 \pm 0.4$ & $1.3 \pm 0.3$ & $1.4 \pm 0.3$ & $1.2 \pm 0.3^{*}$ \\
Wmax $^{*} \mathrm{~W}$ & $70 \pm 30$ & $78 \pm 31^{*}$ & $79 \pm 27$ & $71 \pm 28^{\#}$ \\
\hline
\end{tabular}

All values are expressed as mean $\pm \mathrm{sD}, *: \mathrm{p}<0.05 ; * * *: \mathrm{p}=0.001$, paired t-test between baseline and 12 week test; \#: $\mathrm{p}<0.05$; \#\#: $\mathrm{p}<0.01$ unpaired $\mathrm{t}$-test between the changes in both groups. Wmax: maximal workload of the cycle ergometer test. for further abbreviation see legend to table 1 .

Cycle ergometer test. The rehabilitation group showed a significantly $(\mathrm{p}<0.05)$ higher Wmax in the cycle ergometer test after 12 weeks than at baseline (table 3 ). The rehabilitation group showed an improvement in Wmax of $10 \%(70$ to $78 \mathrm{~W})$, whilst the exercise tolerance of the control group decreased by $9 \%$, the difference being significant $(\mathrm{p}<0.01)$. The $\dot{\mathrm{V}}_{\mathrm{O}_{2}}$-symptom limited $\left(\dot{\mathrm{V}}_{\mathrm{O}_{2}}-\mathrm{SL}\right)$ was also significantly $(\mathrm{p}<0.05)$ higher in the rehabilitation group after 12 weeks compared to baseline, whilst the control group showed a decrease. The change in both groups was significantly $(\mathrm{p}<0.05)$ different.

Relationship between outcome measures. We found no significant correlation between the baseline score of the dimensions Dyspnoea, Fatigue, Emotion, and Mastery and the baseline exercise tolerance for both groups. The change of the dimensions Dyspnoea, Fatigue, Emotion, and Mastery did not correlate with the change in exercise tolerance, either for the whole study population, or for the rehabilitation group alone. 


\section{Discussion}

Our study shows an improvement in quality of life in patients with COPD after 12 weeks of rehabilitation at home. The dimensions Dyspnoea, Fatigue, Emotion, and Mastery of the Chronic Respiratory Questionnaire (CRQ) showed a highly significant improvement in the rehabilitation group, whilst no significant changes were observed in the control group. The improvement in the dimensions Dyspnoea, Emotion, and Mastery in the rehabilitation group was also significantly different compared to the change in the control group. As expected, spirometry did not improve. Although exercise performance improved, this did not correlate with improvement in quality of life.

In a controlled study, GUYATT and co-workers [10] also used the CRQ, but found no change in quality of life after inspiratory muscle training (IMT) at home. This finding might have been expected because DeKHUIJZEN et al. [14] had already shown that IMT alone did not influence psychological parameters, although they did not use the CRQ. On the other hand, they showed that a combination of IMT and conventional rehabilitation decreased anxiety and depression. Several other studies [19-21] have also shown that a comprehensive approach, i.e. physiotherapy, education, and vocational counselling, may lead to an improvement in psychological status. Some studies [19, 20, 22, 23] also showed improvement in the quality of life, but they did not assess it systematically by means of a valid questionnaire. Studies that showed an improved quality of life by using valid questionnaires, like the CRQ, were mostly carried out in a clinical setting without a control group [5, 9, 24]. On the other hand, studies [19, 21, 25, 26] that investigated the effects of a comprehensive rehabilitation programme at home did not assess the change in quality of life. Our study is the first to show that a comprehensive programme of rehabilitation carried out in a home care setting improves both exercise tolerance and quality of life, as compared to a control group.

An important question remaining is whether this improved quality of life, as assessed by the CRQ, is of clinical relevance. GuYATT and co-workers [5] defined improvement in quality of life as an increase of at least four points in the raw score for physical function (Dyspnoea and Fatigue) or emotional function (Emotion and Mastery), with a total improvement of at least four points. It was their impression, after extensive clinical experience with the CRQ [5], that patients with an increase of at least four points find their quality of life improved, whilst patients with a score below four points find their quality of life unchanged. Although the definition of GuYATT and co-workers [5] of an improved quality of life is somewhat arbitrary, we think that the total improvement of 14 points for the dimensions Dyspnoea, Fatigue, Emotion and Mastery in our study is clinically relevant.

JONES et al. [8] and GUYATT [27] advocated the use of disease-specific questionnaires to assess quality of life. Therefore, in our study we used the Chronic Respiratory Questionnaire (CRQ), which proved to be precise, valid, and sensitive [9]. Although we found that the dimension
Dyspnoea had a lower reliability compared to the other dimensions, it was shown to be sensitive to change in this study. Therefore, we agree with GuYATT and coworkers that the CRQ is a reliable and valid tool to measure quality of life. The CRQ determines both physical and emotional function, which encompasses the term quality of life [28]. The use of the CRQ was investigated by MoRGAN [29], who concluded that the questionnaire has the capacity to identify changes after intervention, in patients with COPD.

We also measure physiological functions. In accordance with most studies we found no improvement in lung function in the rehabilitation group. On the other hand, the control group showed a significant decrease in both $\mathrm{FEV}_{1}$ and IVC after merely 12 weeks. This unexpected finding is in contrast with a study by McGAVIN et al. [25], who found no changes in their control group. Although the patients in the rehabilitation group, in contrast with the control group, visited their general practitioner once a month, this was only to supervise their clinical status according to a checklist. The maintenance treatment in both groups did not change during these 12 weeks, and patients in both groups received oral corticosteroids and antibiotics for an exacerbation in a standardized way. There was no difference in the number of exacerbations during 12 weeks between both groups. It is known that lung function deteriorates in COPD, but the decline in $\mathrm{FEV}_{1}$ averages about $50 \mathrm{ml} \cdot \mathrm{yr}^{-1}$ [30]. At this moment, we have no explanation for the large decrease in lung function in our control group. Follow-up of the patients has to show whether this finding is due to change or a real observation.

Our study showed a minor, but significant improvement in exercise capacity on the cycle ergometer test, although lung function did not improve. This finding is compatible with rehabilitation studies in a clinical setting $[14,31]$, and with a home rehabilitation programmes $[25$, 26]. Because the patients in the rehabilitation group trained at home on a home-trainer, this increase in exercise capacity might be due to familiarization with the bicycle, in contrast to the control group. However, not only the Wmax but also $\dot{\mathrm{V}}_{2}$-SL improved in the rehabilitation group. The combination of an increased Wmax and $\dot{\mathrm{V}}_{\mathrm{O}_{2}}$-SL must be considered to be influenced by motivation and effort [32], and not only an increased efficiency due to familiarization. At the same time, there is a decrease in maximal workload in the control group which might be explained by their fall in lung function. However, we did not find a correlation between the fall in lung function and the decrease in exercise capacity in the control group. As far as we know, no other study has found this correlation either.

The increase in exercise tolerance was not associated with an improved quality of life, suggesting that a subjective parameter, such as quality of life, is not influenced by exercise tolerance. On the other hand, GuYatT and co-workers [9] did find a correlation between the improvement in the dimension Dyspnoea and the improved exercise tolerance after a rehabilitation programme. However, GUYATT and co-workers [9] assessed exercise capacity by a 6 min walk test, whilst we used 
cycle ergometer test. At the same time, GuYatT and coworkers [33] had already shown in a previous study that Dyspnoea correlated with the walking distance and not with cycle ergometer tests.

In summary, our study showed that rehabilitation at home leads to an improved quality of life in COPD patients, which is not associated with an improvement in lung function or exercise tolerance. The improvement of quality of life is probably due to the comprehensive care of the rehabilitation programme and not only to a part of it. However, our study investigated only quality of life immediately after rehabilitation at home. An important question remains, namely how long this improvement of quality of life will last. Therefore, further long-term rehabilitation studies, including assessment of quality of life, need to be carried out.

Acknowledgement: The authors thank the lung function laboratory staff of Beatrixoord for their technical assistance in the performance of this study. They also thank H.A.A.M. Gosselink and R.V.M. Chadwick-Straver of the Department of Physiotherapy, University Hospital of Amsterdam (VU), for their translation of the CRQ into Dutch.

\section{References}

1. McSweeny AJ, Grant I, Heaton RK, Adams KM, Timms RM. Life quality of patients with chronic obstructive pulmonary disease. Arch Intern Med 1982; 142: 473-478.

2. Prigatano GP, Wright EC, Levin D. Quality of life and its predictors in patients with mild hypoxemia and chronic obstructive pulmonary disease. Arch Intern Med 1984; 144: 1613-1619.

3. Schrier AC, Dekker FW, Kaptein AA, Dijkman JH. Quality of life in elderly patients with chronic nonspecific lung disease in family practice. Chest 1990; 98: 894-899.

4. Traver GA. Measures of symptoms and life quality to predict emergent use of institutional health care resources in chronic obstructive airways disease. Heart Lung 1988; 17: 689-697.

5. Guyatt GH, Berman LB, Townsend BA. Long-term outcome after respiratory rehabilitation. Can Med Assoc J 1987; 137: 1089-1095.

6. Kaplan RM, Atkins CJ, Timms R. Validity of a wellbeing scale as an outcome measure in chronic obstructive pulmonary disease. J Chron Dis 1984; 37: 85-95.

7. Bergner M, Bobbitt RA, Carter WB, Gilson BS. The Sickness Impact Profile: development and final revision of a health status measure. Med Care 1981; 19: 787-805.

8. Jones PW, Quirk FH, Baveystock CM, Littlejohns P. A self-complete measure of health status for chronic airflow limitation. Am Rev Respir Dis 1992; 145: 1321-1327.

9. Guyatt GH, Berman LB, Townsend M, Pugsley SO, Chambers LW. A measure of quality of life for clinical trials in chronic lung disease. Thorax 1987; 42; 773-778.

10. Guyatt G, Keller J, Singer J, Halcrow S, Newhouse M. Controlled trial of respiratory muscle training in chronic airflow limitation. Thorax 1992; 47: 598-602.

11. Jacobson E. In: Progressive relaxation. Chicago, University of Chicago Press, 1938.

12. Casciari RJ, Firshter RD, Harrison A, Morrison JT, Blackburn C, Wilson AF. Effects of breathing retraining in patients with COPD. Chest 1981; 79: 393-398.

13. Ries AL, Ellis B, Hawkins RW. Upper extremity exercise training in chronic obstructive pulmonary disease. Chest 1988; 93: 688-692.
14. Dekhuijzen PNR, Beek MM, Folgering HT, Van Herwaarden CL. Psychological changes during pulmonary rehabilitation and target-flow inspiratory muscle training in COPD patients with a ventilatory limitation during exercise. Int J Rehabil Res 1990; 13 (2): 109-117.

15. Allison JA, Samios R, Anderson SD. Evaluation of exercise training in patients with chronic airway obstruction. Phys Ther 1981; 61: 1273-1277.

16. Quanjer PH, ed. Standardized lung function testing. Report of working party for "Standardization of Lung Function Tests". European community for Coal and Steel, Luxembourg. Bull Eur Physiopathol Respir 1983; 19 (Suppl. 5): 1-95.

17. Derogatis LR, Cleary PA. Confirmation of the dimensional structure of the SCL-90: a study in construct validity. J Clin Psychol 1977; 33: 981-989.

18. Guyatt GH, Townsend M, Keller JL, Singer J. Should study subjects see their previous responses: data from a randomized 18 control trial. J Clin Epidemiol 1989; 42: 913-920.

19. Haas A, Cardon H. Rehabilitation in chronic obstructive pulmonary disease. A five year study of 252 male patients. Med Clin North Am 1969; 53: 593-606.

20. Petty TL, Nett LM, Finigan MM, et al. A comprehensive care program for chronic airway obstruction. Ann Intern Med 1969; 70: 1109-1120.

21. Agle DP, Baum GL, Chester EH, Wendt M. Multidiscipline treatment of chronic pulmonary insufficiency. 1. Psychologic aspects of rehabilitation. Psychosom Med 1973; 35 (1): 41-49.

22. Cherniack RM, Handford RG, Svanhill E. Home care of chronic Respiratory Disease. J Am Med Assoc 1969; 208: 821-824.

23. Petty TL. Ambulatory care for emphysema and chronic bronchitis. Chest 1970; 58: 441-448.

24. Bebout DE, Hodgkin JE, Zorn EG, Yee AR, Sammer EA. Clinical and physiological outcomes of a university hospital pulmonary rehabilitation program. Respir Care 1983; 28: $1468-1473$.

25. McGavin CR, Gupta SP, Lloyd EL, McHardy JR. Physical rehabilitation for the chronic bronchitic: results of a controlled trial of exercises in the home. Thorax 1977; 32: 307-311.

26. Strijbos JH, Koëter GH, Meinesz AF. Home care rehabilitation and perception of dyspnea in chronic obstructive pulmonary disease patients. Chest 1990; 97: 109s-110s.

27. Guyatt G. Measuring health status in chronic airflow limitation. Eur Respir J 1988; 1: 560-564.

28. Berger M. Measurement of health status. Med Care 1988; 5 (23): 696-704.

29. Morgan MDL. Experience of using the CRQ (Chronic Respiratory Questionnaire). Respir Med 1991; 85 (Suppl. B): $23-24$.

30. Anthonisen NR, Wright EC, Hodgkin JE. Prognosis in chronic obstructive pulmonary disease. Am Rev Respir Dis 1986; 133: 14-20.

31. Cockcroft GH, Saunders MJ, Berry G. Randomized controlled study of rehabilitation in chronic respiratory disability. Thorax 1981; 36: 200-203.

32. Casaburi R. Exercise training in Chronic Obstructive Lung Disease. In: Casaburi R, Petty TL, eds. Principles and Practice of pulmonary rehabilitation. Philadelphia, W.B. Saunders Co., 1993; pp. 204-224.

33. Guyatt GH, Thompson PJ, Berman LB, et al. How should we measure function in patients with chronic lung disease? J Chronic Dis 1985; 38: 517-524. 